\title{
EFEKTIVITAS MODEL PEMBELAJARAN KOMUNIKASI KESEHATAN BERBASIS PENDIDIKAN KARAKTER TERHADAP PENINGKATAN PRESTASI BELAJAR MAHASISWA KEBIDANAN
}

\author{
Siti Noorbaya ${ }^{1}$, Annisa Ul Mutmainnah ${ }^{2}$, Mita Amriana $^{3}$ \\ ${ }^{1}$ Akademi Kebidanan Mutiara Mahakam \\ ${ }^{2}$ Akademi Kebidanan Mutiara Mahakam \\ ${ }^{3}$ Ikatan Alumni Mutiara Mahakam \\ Email: Sitinoorbayanaz.y@gmail.com,annisamutmainnah11@gmail.com \\ $\begin{array}{ll}\text { Dikirim } & : \text { 30 Agustus } 2019 \\ \text { Diterima } & : \text { 20 September } 2019 \\ \text { Dipublikasi } & : 28 \text { September } 2019\end{array}$ \\ ABSTRACT \\ Health communication is one of the core compulsory subjects for midwifery \\ students. The character-based health communication learning model is a study with the \\ aim to find out the effectiveness of the character education-based health communication \\ learning model with a specific target of improving student achievement. In this study the \\ method used was Pre-Experimental with Posttest Only Control Group Design with a \\ sample of 70 students divided into 2 groups: 35 treatment group respondents and 35 \\ control group respondents. The results of the study of the effectiveness of health \\ education learning models based on character education on improving learning \\ achievement, interpretation of the results of the normality test data of the treatment \\ group has a sig value of 0.200>0.05, and the control group has a sig value of 0.129> \\ 0.05, meaning that the data is normally distributed. Results of Data Analysis using the \\ Independent Sample T-Test of $0.035<0.05$, there is a significant difference between the \\ learning outcomes of the experimental / treatment group and the control group. From \\ the results of the study it can be concluded that the character-based health \\ communication learning model given to midwifery students can improve student learning
} achievement

Keywords: Health Communication, Character Education, Learning Achievement 
Jurnal Kebidanan Mutiara Mahakam, Vol 7 , No 2, 2019, Hal 85-91

\section{PENDAHULUAN}

Pendidikan merupakan kunci pembangunan untuk sekarang dan masa yang akan datang. Melalui Pendidikan diharapkan setiap individu dapat meningkatkan kualitas dirinya baik dari segi pengetahuan, wawasan serta dari segi keterampilan agar setiap indvidu mampu berpartisipasi dalam gerak pembangunan. Dunia Pendidikan adalah suatu lembaga terpenting dalam membentuk dan mengembangkan generasi bangsa, yakni masyarakat agar dapat menghadapi tantangan-tantangan yang ada akibat perkembangan zaman diantaranya melalui pemberian pengetahuan dan keterampilan tersebut.

Dalam Bab I UU Tentang Pendidikan Tinggi No. 12 Tahun 2012 mengenai ketentu an umum, pada pasal 1 ayat 1 dikatakan bahwa Pendidikan adalah usaha sadar dan terencana untuk mewujudkan suasana belajar dan proses pembelajaran agar peserta didik secara aktif mengembangkan potensi dirinya untuk memiliki kemampuan spiritual keagamaan, pengendalian diri, kepribadian, kecerdasan, akhlak mulia, serta keterampilan yang diperlukan dirinya, masyarakat, negara dan bangsa.

Pendidikan tinggi adalah jenjang pendidikan tinggi setelah pendidikan menengah mencakup program diploma, program sarjana, program magister, program doktor dan program profesi, serta program spesialis. Yang diselenggarakan oleh perguruan tinggi berdasarkan kebudayaan bangsa Indonesia.

Dosen adalah pendidik profesioanal dan ilmuan dengan tugas utama mentransformasikan, mengembangkan, dan menyebarluaskan ilmu, pengetahuan dan tekhnologi melalui pendidikan, penelitian dan pengabdian kepada masyarakat.

Russel Williams mengilustrasikan bahwa karakter ibarat"otot", dimana"otot-otot" karakter akan menjadi lembek apabila tidak pernah dilatih, dan akan kuat dan kokoh kalua sering dipakai. Seperti seorang binaragawan (body budler) yang terus menerus berlatih untuk membentuk ototnya, "otot-otot" karakter juga akan terbentuk dengan praktik-praktik latihan yang akahirnya akan menjadi kebiasaan (habit). 


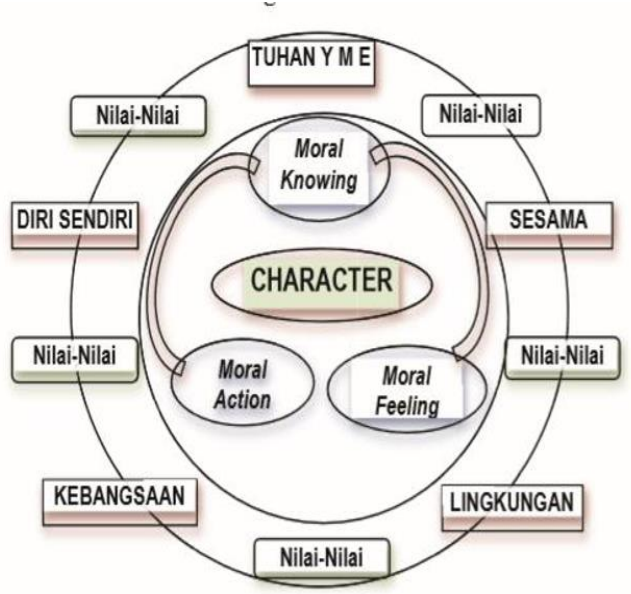

Gambar 1.1 Karakter

Pendidikan karakter bukanlah suatu topik yang baru dalam Pendidikan. Pada kenyaataannya pendidikan karakter ternyata sudah seumur dengan pendidikan itu sendiri. Berdasarkan penelitian sejarah dari seluruh negara yang ada di dunia ini pada dasarnya Pendidikan memiliki dua tujuan, yaitu membimbing para pembelajara untuk menjadi cerdas dan memiliki perilaku berbudi (Lickona, 2013).

Karakter adalah usaha yang dilakukan untuk membentuk kepribadian pelajar. Bila ditelusuri asal karakter berasal dari bahasa latin "kharassein" "kharax", dalam Bahasa Inggris : character dan dalam bahasa Indonesia "karakter", Yunani character, dari charassein yang berarti tajam, membuat dalam. Dalam kamus Poerwadarminta, karakter diartikan sebagai tabiat, watak, sifat-sifat kejiwaan, akhlak atau budi pekerti yang membedakan seseorang dengan yang lain. Nama dari seluruh ciri pribadi yang meliputi hal-hal seperti perilaku, kebiasaan, kesukaan, ketidaksukaan, kemampuan, kecenderungan, potensi, nilai-nilai dan pola -pola pemikiran. Pendidikan karakter adalah Pendidikan untuk membentuk kepribadian seseorang melalui pendidikan budi pekerti, yang hasilnya terlihat dalam tindakan nyata seseorang. (Annisyifa Hilda, 2014).

Komunikasi merupakan seni penyampaian informasi (pesan, ide, sikap/gagasan dari komunikator untuk mengubah/membentuk prilaku komunikan (pola, sikap, pandangan dan pemahaman ke pla pemahaman yang dikehendaki Bersama. Sedangkan komunikasi kesehatan adalah bentuk komunikasi yang digunakan oleh bidan dalam memberikan asuhan kebidanan kepada klien. (Noorbaya Siti, 2018).

Mata kuliah komunikasi kesehatan dalam praktik kebidanan adalah mata kuliah dasar program studi, mata kuliah ini memberi kesempatan mahasiswa untuk menerapkan komunikasi interpersonal dan konseling dalam lingkup praktik kebidanan dan 
Jurnal Kebidanan Mutiara Mahakam, Vol 7 , No 2, 2019, Hal 85-91

memperhatikan aspek budaya yang didasari dengan filosofi, etikolegal, keilmuan yang menekankan pada upaya promosi kesehatan dengan menitik beratkan pada pemberdayaan individu, keluarga, kelompok dan masyarakat untuk memelihara dan meningkatkan kesehatannya.

Proses pembelajaran komunikasi kesehatan dapat dilaksanakan di kelas, laboratorium dan klinik. Dalam pelaksanaan pembelajaran terdapat beragam metode pembelajaran yang dapat digunakan untuk Student Centre Learning (SCL), diantaranya adalah : (1) Small Group Discussion; (2) Role Play dan Simulation; (3) Case Study; (4) Discovery Learning (DL); (5) Self-Directed Learning (SDL); (6) Cooperative Learning (CL); (7) Collaborative Learning (CbL); (8) Contextual Instruction (CI); (9) Project Based Learning (PjBL) ; (10) Problem Based Learning (PBL), (Panduan teknologi pembelajaran pendidikan tinggi vokasi, Kemenristek Dikti, 2016).

Proses pembelajaran dengan menggunakan ceramah tanya jawab, diskusi, penugasan, kuis. Ditunjang dengan pembelajaran menggunakan web yang dapat diakses oleh mahasiswa untuk mengunduh materi, menjawab kuis dan berdiskusi dengan dosen atau sesama mahasiswa di luar jam perkuliahan. Dilaksanakan dikelas, laboratorium (baik di kampus maupun dilahan praktek) dengan menggunakan metode simulasi, demonstrasi, role play, pre-post conference, bed side teaching, coching dan lain-lain. (Buku Kurikulum D-III Kebidanan, 2015).

\section{METODE PENELITIAN}

Penelitian ini dilakukan di Akademi Kebidanan Mutiara Mahakam Samarinda pada mahasiswi Semester 2 pada bulan Maret-Juli tahun 2019. Dalam penelitian ini metode yang digunakan Pra Eksperimental dengan rancangan Posttest Only Control Group Design dengan jumlah sampel 70 mahasiswa yang terbagi 2 kelompok yaitu 35 responden kelompok perlakuan dan 35 responden kelompok control. Subyek penelitian ini adalah mahasiswa semester II program studi Diploma III Kebidanan. Variabel independent adalah model pembelajaran komunikasi kesehatan berbasis pendidikan karakter dengan menggunakan pilar 1 tanggung jawab, disiplin dan mandiri (kode 1) dan pilar 2 percaya diri, kreatif dan bekerja keras (kode 2). Sedangkan variable dependent adalah prestasi belajar mahasiswa.. 
Jurnal Kebidanan Mutiara Mahakam, Vol 7 , No 2, 2019, Hal 85-91

\section{HASIL DAN PEMBAHASAN}

Hasil penelitian tentang efektivitas model pembelajaran komunikasi kesehatan berbasis pendidikan karakter terhadap prestasi belajar mahasiswa kebidanan.

\begin{tabular}{lccccc}
\multicolumn{6}{l}{ Tabel 1. Karakteristik Sampel (Data Kontinu) } \\
\hline Kelompok & (n) & Mean & SD & Min. & Max. \\
\hline Eksperimen & 35 & 82 & 7.7 & 70 & 97 \\
Kontrol & 35 & 78.2 & 7.3 & 67 & 93 \\
\hline
\end{tabular}

Pada tabel 1 dapat diketahui bahwa nilai rata-rata untuk kelompok eksperimen adalah 82 dengan nilai minimal 70 dan nilai maksimal 97, sedangkan nilai rata-rata untuk kelompok kontrol adalah 78.2 dengan nilai minimal 67 dan nilai maksimal 93.

Tabel 2. Karakteristik Sampel (Data Kategorikal)

\begin{tabular}{lcc}
\hline \multicolumn{1}{c}{ Hasil Belajar } & (n) & \% \\
\hline Kelompok Eksperimen & & \\
Baik & 33 & 94.3 \\
Kurang & 2 & 5.7 \\
\hline Kelompok Kontrol & & \\
Baik & 27 & 77 \\
Kurang & 8 & 23 \\
\hline
\end{tabular}

Pada tabel 1 dapat diketahui bahwa nilai rata-rata untuk kelompok eksperimen adalah 82 dengan nilai minimal 70 dan nilai maksimal 97, sedangkan nilai rata-rata untuk kelompok kontrol adalah 78.2 dengan nilai minimal 67 dan nilai maksimal 93.

Tabel 3. Perbedaan Hasil Belajar Mahasiswa (Postest) pada Kelompok Eksperimen dan Kelompok Kontrol.

\begin{tabular}{|c|c|c|c|}
\hline \multirow[t]{2}{*}{ Kelompok } & \multicolumn{2}{|c|}{ Hasil Belajar } & \multirow{2}{*}{$\begin{array}{c}\text { p- } \\
\text { value }\end{array}$} \\
\hline & Kurang & Baik & \\
\hline Eksp & 2 & 33 & 0,035 \\
\hline Kontrol & 8 & 27 & \\
\hline
\end{tabular}

Berdasarkan hasil uji T-Test diperoleh nilai $\mathrm{p}$-value 0,035 . Interpretasi nilai $\mathrm{p}<0,05$, maka dapat disimpulkan bahwa terdapat perbedaan hasil belajar mahasiswa secara signifikan antara kelompok eksperimen dan kelompok control.

Hal ini menunjukkan bahwa Model Pembelajaran Komunikasi Kesehatan Berbasis Pendidikan Karakter efektif meningkatkan prestasi belajar mahasiswa kebidanan yaitu meningkatnya hasil belajar mahasiswa mata kuliah komunikasi kesehatan. Hasil belajar ini diperoleh dari penilaian ujian akhir semester dalam bentuk IPK, tidak hanya peningkatan nilai penelitian kelompok yang mendapat perlakuan lebih menonjolkan karakter prilaku didalam kelas. Hal ini sejalan dengan penelitian oleh Pranowo (2013) dengan hasil kesimpulan bahwa pendidikan karakter meningkatkan 
Jurnal Kebidanan Mutiara Mahakam, Vol 7 , No 2, 2019, Hal 85-91

keterampilan berbicara dalam berbahasa dengan melalui metode penerapan bermain peran dalam mata kuliah expression orale dan mahasiswa antusias mengikuti kuliah, merasa tidak tertekan, bebas berekspresi dan kelas lebih aktif serta peningkatan prestasi belajar .

\section{SIMPULAN}

Berdarkan hasil uji normalitas data kelompok perlakuan memiliki nilai sig 0,200 dan kelompok kontrol memiliki nilai sig 0,129. Interpretasi nilai $p>0,05$, artinya data berdistribusi normal. Hasil Analisis Data dengan Uji Independent Sample T-Test diperoleh nilai p-value 0,035 , maka dapat disimpulkan terdapat perbedaan signifikan antara hasil belajar mahasiswa kelompok eksperimen/ perlakuan dengan kelompok kontrol.

Dari hasil penelitian dapat disimpulkan bahwa model pembelajaran komunikasi kesehatan berbasis karakter yang diberikan kepada mahasiswa kebidanan dapat meningkatkan prestasi belajar mahasiswa. Bagi pengampu mata kualiah komunikasi dalam praktik kebidanan sebaiknya lebih meningkatkan komunikasinya terutama antarpersonal agar tidak terjadi timbulnya miscommunication antara pengampu mata kuliah dengan peserta didik. Kembangkan model pembelajaran komunikasi kesehatan berbasis karakter tidak hanya di satu mata kuliah sebaiknya semua mata kuliah RPS di program studi tersebut telah berbasis pendidikan karakter.

\section{DAFTAR PUSTAKA}

Ali, Ramdhani M. 2014. Lingkungan Pendidikan dalam Implementasi Pendidikan Karakter. Jurnal Pendidikan Universitas Garut, Vol 08; No. 01; 2014.

Annisyifa, Hilda. 2014. Pendidikan Karakter dalam Perspektif Islam. Jurnal Pendidikan Universitas Garut, Vol 08; No. 01; 2014.

Kemenristek Dikti, 2016. Panduan teknologi pembelajaran pendidikan tinggi vokasi.

Kristiawan, M. 2017. Desain Pembelajaran SMA Plus Negeri 2 Banyuasin III Berbasis Karakter Di Era Masyarakat Ekonomi ASEAN. Jurnal Iqra Jurnal Kajian Pendidikan (Eduacational Journal).

Lickona, Thomas. 2003. Education for Character, How Our Schools Can Teach Respect and Responsibility, Bantam Books, New York.

Megawangi, Ratna. 2003. Pendidikan Karakter untuk Membangun Masyarakat Madani. IPPK Indonesia Heritage Foundation. 
Jurnal Kebidanan Mutiara Mahakam, Vol 7 , No 2, 2019, Hal 85-91

Menteri Pendidikan Nasional. 2010. Undang-undang Republik Indonesia No. 20 tahun 2003 tentang SISDIKNAS \& Perarturan Pemerintah Republik Indonesia Tahun 2010 tentang Penyelenggaraan Pendidikan Serta Wajib Belajar.

Mukhadis, A. 2013. Sosok Manusia Indonesia Unggul Dan Berkarakter Dalam Bidang Teknologi Sebagai Tuntutan Hiduo di Era Globalisasi. Jurnal Pendidikan Karakter, tahun III Nomer 2 Juni.

Ngalim, 2006. Ilmu Pendidikan. Remaja Karya. Jakarta.

Noorbaya, S., Johan, H. and Rahayu, S., 2018. Komunikasi Kesehatan. Gosyen Publishing.

Notoatmodjo, Soekidjo. 2010. Metodologi Penelitian Kesehatan. Rineka Cipta. Jakarta

Pranowo, D.J. 2013. Implementasi pendidikan Karakter kepedulian dan Kerjasama pada Matakuliah Keterampilan berbicara bahasa inggris dengan metode bermain peran. Jurnal Pendidikan Karakter, tahun III Nomer 2 Juni.

Pritchard, I. 2012. Character education: Research Prospects and Problems. American Journal Of Education. Vol .96. No 4. Agustus.

Simon Philips. 2008. Refleksi Karakter Bangsa.

Sugiono. 2010. Metode Penelitian Kuantitatif Kualitatif R dan D. Alfabeta Bandung.

Suyanto. 2009. Urgensi Pendidikan Karakter.

Panduan Akademik Akademi Kebidanan Mutiara Mahakam tahun 2015. 